\title{
LOBULAR CARCINOMA IN SITU DEVELOPING IN LACTATING ADENOMA OF THE BREAST: A CASE REPORT
}

\author{
Tatsumasa Andoh ${ }^{1)}$, Noritaka Sugamata ${ }^{1)}$, Toshiro Ikeya ${ }^{1)}$, \\ Hideaki Itoh $^{2)}$, Yuichi Iino ${ }^{3)}$, Yasuo Morishita ${ }^{4}$ \\ 1) Department of Surgery, and 2) Department of Pathology Maebashi Red Cross Hospital \\ 3) Department of Emergency and Critical Care Medicine and \\ 4) Second Department of Surgery, Gunma University School of Medicine
}

\begin{abstract}
We experienced a rare case of lobular carcinoma in situ developing in lactating adenoma of the breast. A 32-year-old woman had a lump in the upper lateral quadrant of the left breast. Excisional biopsy of the breast tumor was performed and histological examination confirmed a diagnosis of lactating adenoma and lobular carcinoma in situ. The patient has been followed up at our outpatient clinic without additional resection and there has been no evidence of recurrence.
\end{abstract}

Key words: Lactating adenoma, Lobular carcinoma in situ, Breast (Kitakanto Med.J. 50 (1) : 51 53, 2000)

\section{INTRODUCTION}

The most common tumor of the breast during pregnancy and nursing is breast cancer. Because of the development of cellular atypia, the diagnosis of breast tumors affected by pregnancy, nursing using aspiration cytology is often difficult. Careful attention should be given to mammary tumors during pregnancy and nursing. The following reports is a case of a nursing woman with lobular carcinoma in situ (LCIS) developing in lactating adenoma of the breast.

\section{CASE REPORT}

A 32-year-old woman had a lump in the upper lateral quadrant of the left breast. The patient noticed the lump during pregnancy in 1991 and following a diagnosis of fibroadenoma, was monitored at our outpatient clinic. The patient noticed growing of the tumor during nursing in 1997 and consulted our hospital. There was no contributory family history. An ovoid tumor, $5.0 \times 4.5 \mathrm{~cm}$ in size, was palpable in the upper lateral quadrant of the left breast. The tumor was smooth, mobile, soft and well circumscribed, and no dimpling sign was observed. A manmmogram of the left breast revealed a tuberous shadow of the tumor, which was smooth with a relatively clear boundary and microcalcification (Fig.1). An ultrasonogram showed an oval-shaped hypoechoic image with clear boundary. A heterogeneous internal echo was observed with a strong echo which indicated the presence of calcifica-

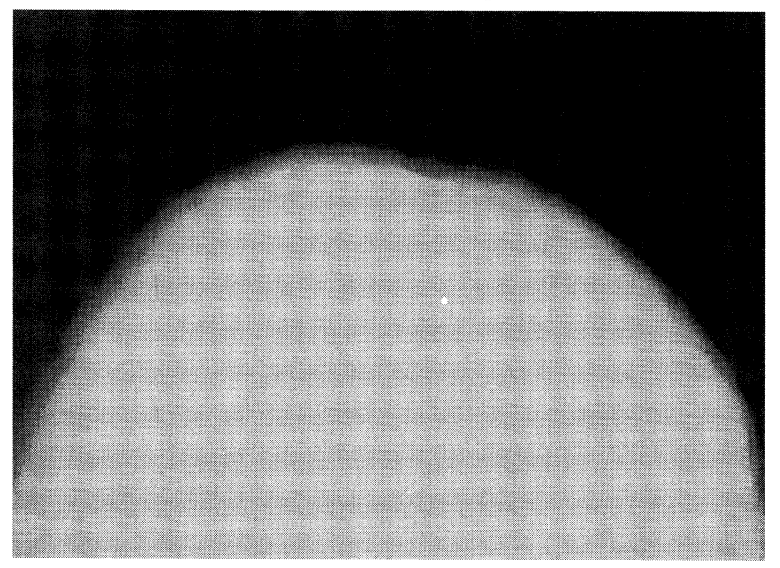

Fig.1 A manmmogram of the left breast reveals a tuberous image of the tumor which had smooth edge. Microcalcification is present. 


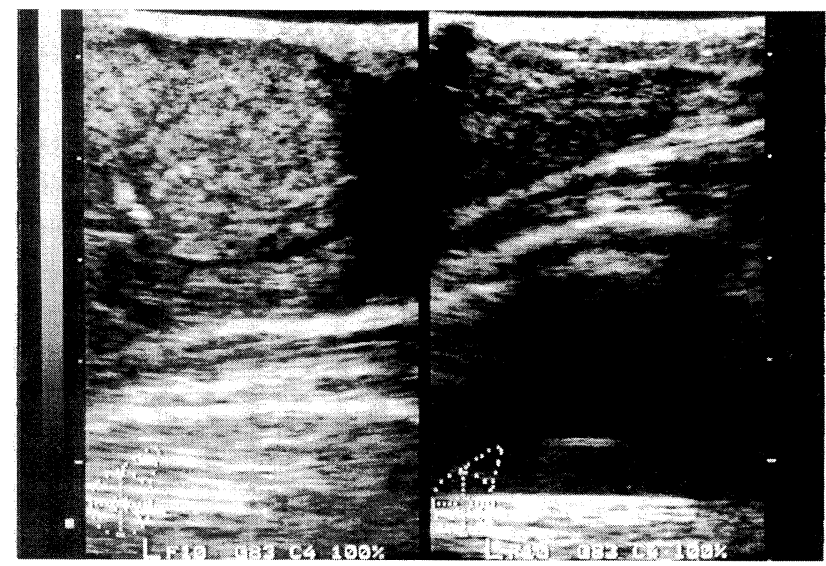

Fig.2 A ultrasonogram shows an oval-shaped hypoechoic image with clear boundary. The heterogeneous internal echo is observed with strong echo suggesting calcification

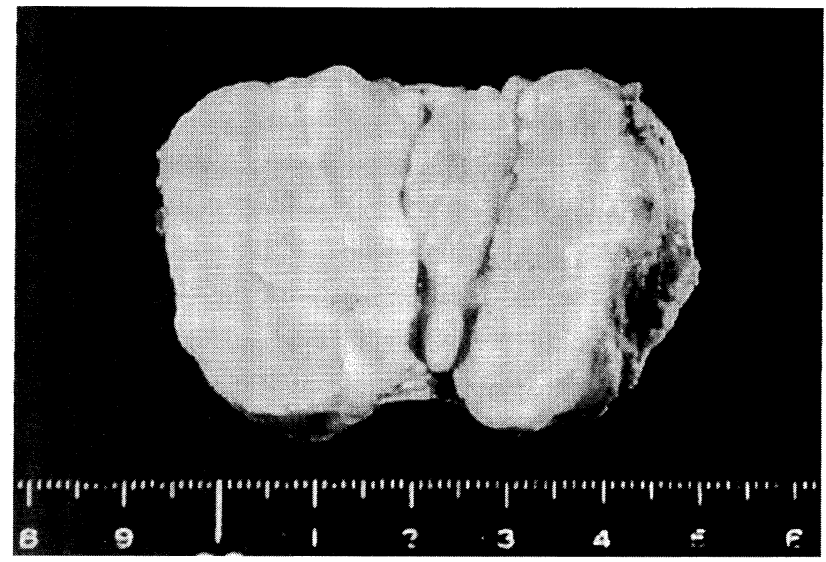

Fig.4 The cut surface is yellow and solid. The tumor is $4.5 \times$ $4.0 \times 3.8 \mathrm{~cm}$ in size.

tion (Fig.2). The above findings were strongly suggestive of fibroadenoma, however a fine needle aspiration biopsy indicated cytologically to be class III (Fig.3). An excisional biopsy of the breast tumor was performed. The tumor, measuring $4.5 \times 4.0 \times 3.8 \mathrm{~cm}$ in size (Fig.4), was easily detached from the surrounding tissues. The tumor was soft and the cut surface was yellow and solid, was covered with a thin capsule. Histologically, glandular epithelial cells in the tumor proliferated markedly, forming tubules or acini. The stroma was sparse. The histological diagnosis in most parts of the tumor was lactating adenoma (Fig.5), however there was evidence of LCIS in the tumor, which measured $6.0 \times 5.0 \mathrm{~mm}$ in size (Fig.6). The tumor was negative for estrogen receptor (ER) and positive for progesterone receptor $(\mathrm{PgR})$ on enzyme immunoassay (ER, $12.7 \mathrm{fmol} / \mathrm{mg}$ protein; PgR, 19.0 $\mathrm{fmol} / \mathrm{mg}$ protein).

The patient has been followed up at our outpatient clinic without additional resection, and there has been no evidence of recurrence.

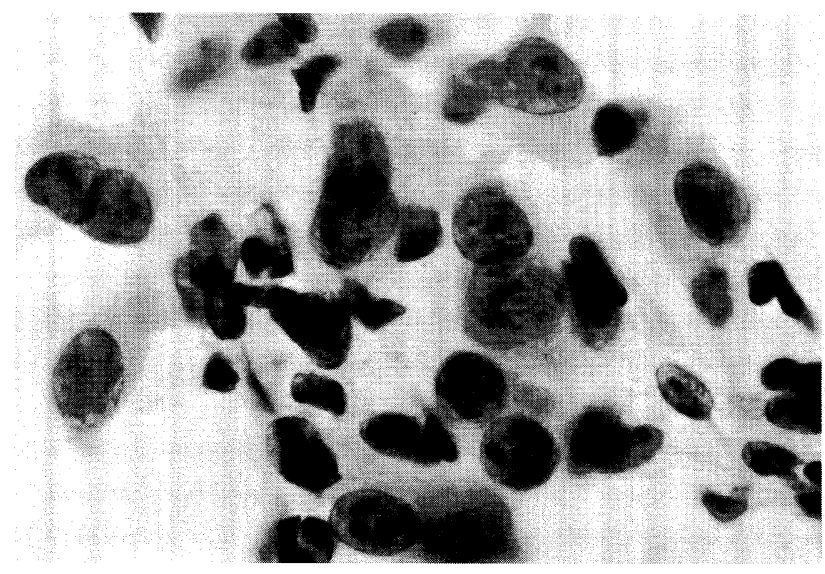

Fig.3 Aspiration biopsy cytology showing atypical cytology (Papanicolaou stain, $\times 130$ ).

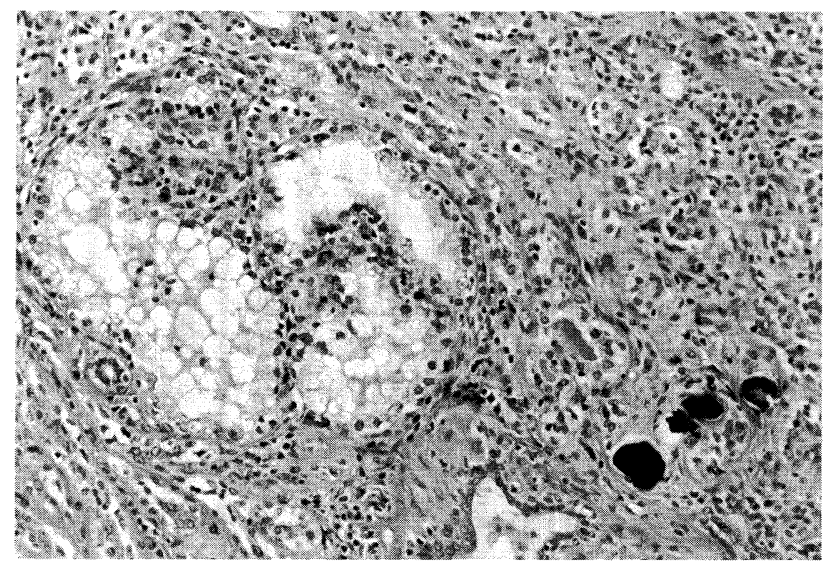

Fig.5 Histologically, glandular epithelial cells in the tumor have proliferated markedly, forming tubules or acini. The stroma is sparse (HE stain, $\times 50$ ).

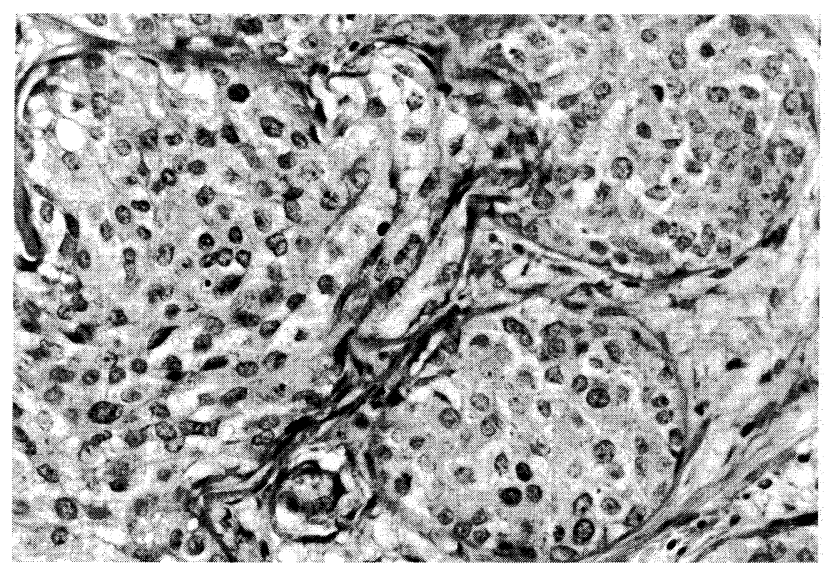

Fig.6 Most of the tumor consists of lactating adenoma and there is lobular carcinoma in situ in the tumor. This carcinoma is $6.0 \times 5.0 \mathrm{~mm}$ in size (HE stain, $\times 100$ ).

\section{DISCUSSION}

According to the General Rules for Clinical and Pathological Recording of Breast Cancer ${ }^{1)}$, benign epithelial tumors of the mammary gland are classified 
into intraductal papilloma or adenoma of the nipple and adenoma. Adenoma is further divided into the subclasses; tubular adenoma and lactating adenoma. The histological characteristics of lactating adenoma, according to Hertel et $\mathrm{al}^{2}$. include ; 1) homogeneous lesion throughout and sharply demarcated from the adjacent mammary tissues; 2) cellular or proliferative elements are limited to epithelial structures; 3) the stroma is composed of the minimum amount of connective tissues necessary to support the glandular tissues; and 4) lactating adenoma develops during pregnancy and nursing periods. Hertel et $\mathrm{al}^{2}$. reported that tubular adenoma and lactating adenoma are originally the same disease and have the same mechanism of onset, but demonstrate different physiological conditions. Meanwhile Persaud et $\mathrm{al}^{3}{ }^{3}$. stated that lactating adenoma is a lesion of fibroadenoma as a result of influences of pregnancy. There has been no established theory on the pathogenesis of these subclasses ${ }^{4}$.

Takai et $\mathrm{al}^{5}$.). reported 12 cases of lactating adenoma all of which were detected during pregnancy and nursing periods. All patients aged between 21 and 39 years old (average, 30.1). The tumor size ranged from 2 to $7.8 \mathrm{~cm}$ in diameter. Of seven patients with the presurgical diagnosis, three were suspected having a malignant tumor based upon aspiration cytology. Breast cancer is the most frequent among mammary tumors which develop during pregnancy and nursing periods. It is however sometimes difficult to evaluate such a tumor through aspiration cytology because cytological features greatly vary and sometimes cause an increased degree of atypia even in a benign tumor due to the influences of pregnancy and lactation.

Hertel et $\mathrm{al}^{2}$. reported the onset of carcinoma 7 years after resection of a lactating adenoma. It is extremely rare however to detect carcinoma within a case of lactating adenoma. Since cytological features are varied and the atypical nature may be facilitated by influences of pregnancy and lactation, biopsy should be performed in order to obtain a diagnosis whenever the mass increases in volume, or the possibility of malignancy cannot be excluded.

LCIS is sometimes identified as a coincidental finding during biopsy of breast tissues. The incidence of multifocality is high and bilateral disease is frequent ${ }^{6}$. Mammography is not effective in detecting LCIS. The risk of subsequent invasive cancer increases with the length of the follow up period and also with age. The incidence of cancer is nine times greater than normal population ${ }^{7}$. Careful and continuous follow up is a necessary this disease.

\section{REFERENCES}

1) Japanese Breast Cancer Society: General Rules for Clinical and Pathological Recording of Breast Cancer, 13 th ed, Kanehara Pub, Tokyo, 1998.

2) Hertel B F, Zaloudek C, Kempson R L. Breast adenomas. Cancer 1976; $37: 2891-2905$.

3) Persaud V, Teleman A, Johdan R. Pure adenoma of the breast. Arch Pathol 1976; 86: 481-483.

4) Kered J, John B, Peter P. Breast tumor of pregnancy (Lactating adenoma). J Pathol 1988; 156 : 37-44.

5) Takai Y, Sato N, Kobayashi I, et al. A case of lactating adenoma of the breast and review of the literature in Japan. Breast Cancer 1996; 3 : 141144.

6) Anderson JA. Lobular carcinoma in situ. A histological study of 52 cases. Acta Pathol Microbiol Acand 1974; 82: 735-741.

7) Rosen PP, Lieberman PH, Braun DW, et al. Lobular carcinoma in situ of the breast. Am $\mathbf{J}$ Surg Pathol 1978; 2: 225-251. 